BULLETIN Bulletin hispanique

HISPANIQUE Université Michel de Montaigne Bordeaux

114-1 | 2012

Varia

\title{
De Francisco a Marco Antonio Aldana pasando por Gaspar Gil Polo
}

Rafael Ramos

\section{CpenEdition}

Journals

Edición electrónica

URL: http://journals.openedition.org/bulletinhispanique/1894

DOI: 10.4000/bulletinhispanique.1894

ISSN: 1775-3821

Editor

Presses universitaires de Bordeaux

Edición impresa

Fecha de publicación: 1 junio 2012

Paginación: 345-365

ISBN: 978-2-86781-812-7

ISSN: 0007-4640

Referencia electrónica

Rafael Ramos, « De Francisco a Marco Antonio Aldana pasando por Gaspar Gil Polo », Bulletin

hispanique [En línea], 114-1 | 2012, Publicado el 01 junio 2015, consultado el 30 abril 2019. URL : http:// journals.openedition.org/bulletinhispanique/1894 ; DOI : 10.4000/bulletinhispanique.1894

Tous droits réservés 


\title{
VARIÉTÉS
}

\section{De Francisco a Marco Antonio Aldana pasando por Gaspar Gil Polo ${ }^{1}$}

\author{
RAFAEL RAMOS \\ Universitat de Girona - España
}

On considère traditionnellement que l'"Aldana " dont Gaspar Gil Polo fait l'éloge à la fin de son Canto de Turia (1564), était Francisco de Aldana, le "divino ". Il est cependant plus probable qu'il se soit agi, en réalité, du poète valencien Marco Antonio Aldana, aujourd'hui pratiquement oublié, mais pourtant fort en vue dans les milieux culturels valenciens du troisième quart du XVI siècle.

Tradicionalmente se ha aceptado que el "Aldana» elogiado por Gaspar Gil Polo al final de su Canto de Turia (1564) era Francisco de Aldana, "el divino". Mas probable, sin embargo, es que se trate del poeta valenciano Marco Antonio Aldana, hoy prácticamente olvidado pero bastante conocido en los ambientes culturales valencianos del tercer cuarto del siglo XVI.

It is traditionally considered that the "Aldana", whom Gaspar Gil Polo praises at the end of his "Canto de Turia" (1564), was Francisco de Aldana, the "divino". It is nonetheless more probable that it was in fact rather the Valencian poet, Marco Antonio Aldana, almost forgotten today, but very much in the public eye within the cultivated circles of the end of the sixteenth century Valencia.

Mots-clés : Marco Antonio Aldana, Francisco de Aldana, Gaspar Gil Polo, Canto de Turia.

1. Este estudio se inscribe dentro del proyecto FFI 2008-05556-C03/FILO subvencionado por el Ministerio de Ciencia e Innovación. Se ha beneficiado, también, de la colaboración de un buen número de amigos, a los que quiero agradecer todo su apoyo: Florence d'Artois (Universitat Autònoma de Barcelona), Emilio Blanco (Universidad Rey Juan Carlos, Madrid), Felicidad Esteban Llorente (Arxiu del Regne de València), Ralph DiFranco (University of Denver), Laura Fernández García (Universitat Autònoma de Barcelona), Ana M. ${ }^{a}$ Gimeno Pascual (Biblioteca de Cort, Palma de Mallorca), Esther González-Ibarra (Biblioteca de la Real Academia de la Historia, Madrid), María Luisa López-Vidriero Abelló (Real Biblioteca, Madrid), Jaume Riera i Sans (Archivo de la Corona de Aragón, Barcelona), Fausto Roldán (Biblioteca de la Fundación Bartolomé March, Palma de Mallorca), Álvaro Soler (Real Armería, Madrid), Jaume Torró (Universitat de Girona) y Xavier Tubau (Universitat Pompeu Fabra, Barcelona).

Bulletin Hispanique, Tome 114, n 1 - juin 2012 - p. 345-365. 
G L destino de algunos textos es convertirse en panteones literarios. Una mera retahíla de nombres y alusiones que tiene su sentido en un momento y un círculo literario concretos pero que, al cabo de unos pocos ańos, fuera del contexto en que se compusieron, pierden totalmente su razón de ser y se transforman en un simple cementerio de personajes en su mayoría más o menos desconocidos, sin otro aliciente que el de servir de entretenimiento a los historiadores de la literatura. Es el caso, sobre todo, de las galerías poéticas con las que determinados escritores pretendieron elogiar a sus compañeros o maestros. Si alguien acude a composiciones como el Elogio de poetas lusitanos de Jacinto Cordeiro (1631), el Laurel de Apolo o El jardin de Lope de Vega (1630 y 1621), la Casa de la Memoria de Vicente Espinel (1591) o el mismísimo Canto de Caliope de Miguel de Cervantes (1585), desde luego, no se sorprenderá lo más mínimo al encontrar en ellas un buen número de autores prácticamente olvidados en nuestros días. Solo una buena anotación, cuando la hay, ayuda al lector contemporáneo a interpretar cabalmente todas esas oscuras menciones, sus encorsetadas, artificiales y repetitivas alabanzas, al hacer aflorar las personalidades implicadas y su importancia en esos ambientes determinados ${ }^{2}$. Uno de los más tempranos ejemplos de este tipo de textos es el Canto de Turia incluido por Gaspar Gil Polo en el libro tercero de su Diana enamorada (1564). El río sale «de una profundísima cueva» y con «ronca y congojada voz» entona una alabanza de los grandes hombres del reino de Valencia: ${ }^{3}$ religiosos, militares, filósofos y sobre todo poetas, desde Jordi de Sant Jordi, Ausiàs March o Jaume Roig hasta los autores coetáneos. El panegírico de estos personajes valencianos, sin embargo, acaba con los siguientes versos, especialmente elogiosos para su protagonista:

Por fin de este apacible y dulce canto, y extremo fin de general destreza, os doy a aquel con quien extraño espanto al mundo ha de causar naturaleza; nunca podrá alabarse un valor tanto, tan rara habilidad, gracia, nobleza, bondad, disposición, sabiduría, fe, discreción, modestia y valentía.

Este es Aldana, el único monarca, [que junto ordena versos y soldados; que en cuanto el ancho mar cińe y abarca con gran razón los hombres señalados en gran duda pondrán si él es Petrarca, o si Petrarca es él, maravillados de ver que, donde reina el fiero Marte, tenga el facundo Apolo tanta parte.

2. Véase ahora el ilustrador trabajo de Pedro Ruiz Pérez, «Espejos poéticos y fama literaria: las epístolas en verso del siglo XVI», Bulletin hispanique, Penser la littérature espagnole, [CVI], 1, 2004, pp. 45-80.

3. Gaspar Gil Polo, Diana enamorada, ed. Francisco López Estrada, Castalia, Madrid, 1988, p. 211. 


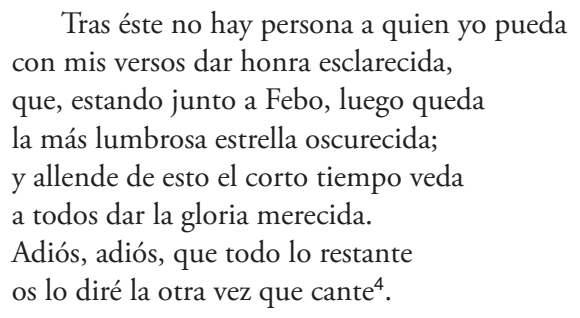

Desde hace siglos, los estudiosos de la literatura han creído ver en estos versos una alusión al gran poeta Francisco de Aldana, «el divino»". La aparición en ellos de las glorias militares en paralelo con las poéticas («que junto ordena versos y soldados»), así como de un perfecto conocimiento de la lengua italiana («en gran duda pondrán si él es Petrarca, | o si Petrarca es él») así parecía indicarlo, así como la desmesura de los elogios ("Tras éste no hay persona a quien yo pueda $\mid$ con mis versos dar honra esclarecida»), que se extienden a lo largo de tres octavas, constituyendo en fin la alabanza más extensa de toda la composición, lo parecía confirmar. Además, y desde ese planteamiento, tampoco han faltado otros eruditos que, con el apoyo de esa hipotética alusión

4. Ibidem, pp. 226-227, aunque restituyo el segundo verso de la segunda octava, omitido en esta edición, de acuerdo con las antiguas impresiones de la obra.

5. La relación ha de empezar, necesariamente, con Francisco Cerdá y Rico, en las «Anotaciones al Canto de Turia» recogidas en su edición de la Diana enamorada (Antonio de Sancha, Madrid, 1778, pp. 439-445), frecuentemente saqueadas por otros editores de los siglos XIX y Xx, pero lo sorprendente es que prosigue con investigadores de la talla de J[osep] Y[xart] (Daniel Cortezo, Barcelona, 1886, p. 376), Rafael Ferreres (Espasa-Calpe, Madrid, 1953, p. 171) o Francisco López Estrada (Castalia, Madrid, 1988, pp. 226-227). Por otro lado ha de contarse la aceptación general que ha recibido la atribución de este elogio entre la mayoría de los estudiosos de la poesía del Siglo de Oro en general o de Francisco de Aldana en particular, como Adolfo de Castro (Poetas líricos de los siglos XVI y XVII, II, Rivadeneyra, Madrid, 1857, p. LXXXV), J. P. Wickersham Crawford ("The Asneida of Cosme de Aldana», Bulletin hispanique, LXXXI, 2 [1933], pp. 107-119, y "Francisco de Aldana: A Neglected Poet of the Golden Age in Spain", Hispanic Review, VII [1939], pp. 48-61), José María de Cossío ("Francisco de Aldana, el Divino», Cruzy raya, núm. 13 [abril, 1934], pp. 113-138, Hombre adentro, Séneca, México, 1941, pp. 1112, y Fábulas mitológicas en España, Espasa-Calpe, Madrid, 1952, p. 196), Alfredo Lefebvre (La poesía del capitán Aldana [1537-1578], Universidad de Concepción, 1953, p. 66), Elias L. Rivers («Francisco de Aldana, el divino Capitán», Revista de estudios extremeños, IX [1953], pp. 451-635 [en concreto, pp. 454 y 577], y Francisco de Aldana, Poesías, Espasa-Calpe, Madrid, 1957, p. XxxI), Juan Chabás (Poetas de todos los tiempos: hispanos, hispanoamericanos, cubanos, Cultural, La Habana, 1964, p. 41), José Guerra Flores, («El hombre interior», Ábside, XXX [1966], pp. 305-311), Luis Guarner (En torno a Lope de Vega. Seis ensayos, Bello, Valencia, 1976, p. 82), Carlos Ruiz Silva («Francisco de Aldana, en el cuarto centenario de su muerte», Revista de Occidente, tercera época, núm. 18 [abril, 1977], pp. 48-52, y Estudios sobre Francisco de Aldana, Universidad de Valladolid, 1981, p. 49), Gonzalo Díaz Díaz (Hombres y documentos de la filosofía española, I, C.S.I.C., Madrid, 1980, p. 147), Raúl Ruiz (Francisco de Aldana, Sonetos, Hiperión, Madrid, 1984, p. 22); D. Gareth Walters (The Poetry of Francisco de Aldana, Tamesis, Londres, 1988, p. 18); Ricardo Senabre (Escritores de Extremadura, Diputación Provincial de Badajoz, 1988, p. 47). 
y algún que otro dato mal interpretado, consideraran Valencia como el lugar de nacimiento de este escritor ${ }^{6}$.

Sin embargo, esa identificación se desvanece de un plumazo si se contempla desde una perspectiva mínimamente crítica. En efecto, en 1564, cuando se publicó la Diana enamorada, Francisco de Aldana era un jovencísimo poeta de unos 25 o 26 años que, por lo que sabemos, todavía no había pisado Espańa; por el contrario, podemos asegurar que hacia esas fechas se encontraba en la Toscana, donde dedicó un soneto al nuevo gobernador de Milán, don Gonzalo Fernández de Córdoba, declamó unas rudas octavas pastoriles en la boda de su hermano Hernando y publicó un juvenil soneto en italiano In risposta a M. Benedetto Varchi, su maestro, al tiempo que el librero Giorgio Marescotti le dedicaba la comedia $L a$ Cecca, de Girolamo Razzi ${ }^{7}$. Además, se trataba de un autor cuya obra era prácticamente desconocida fuera de sus círculos más íntimos. La prueba es que, aparte las obras publicadas por su hermano Cosme de Aldana a partir de 1589 y el poema dedicado a Gabriel Lobo Lasso de la Vega, que tiene una transmisión textual independiente ${ }^{8}$, solo se conservan un puñado de composiciones suyas repartidas en unos pocos manuscritos

6. Vicente Ximeno, Escritores del reino de Valencia, I, Joseph Estevan Dolz, Valencia, 1742 [reimp. facs. Liberías París-Valencia, Valencia, 1980], p. 171-172, basándose en una alusión mal interpretada de Vicente Mariner (véase el apéndice a este estudio) y en noticias infundadas que le había suministrado Gregorio Mayans (cf. Antonio Mestre, El mundo intelectual de Mayans, Ayuntamiento de Oliva-Caja de Ahorros y Monte de Piedad de Valencia, Valencia, 1978, pp. 204-205). Le siguen ciegamente Francisco Javier Lampillas, Saggio storico-apologetico della letteratura spagnuola, III, Felice Repetto, Génova, 1781, p. 159; Justo Pastor Fuster, Biblioteca valenciana de los escritores que florecieron hasta nuestros días, I, José Ximeno, Valencia, 1827 [reimp. facs. Librerías París-Valencia, 1980], pp. 136-137; Andrés Bello, Obras completas, VI, Estudios filológicos, I, ed. Samuel Gili y Gaya, Ministerio de Educación-Biblioteca Nacional de Venezuela, Caracas, 1955, p. 108; Adolfo de Castro, Poetas líricos de los siglos XVI y XVII, II, p. LXXXIV; Ángel Salcedo y Ruiz, Resumen histórico-crítico de la literatura española, Saturnino Calleja Fernández, Madrid, 1910, p. 264; Manuel de Montoliu, Literatura castellana, Cervantes, Barcelona, 1930, p. 278; J. P. Wickersham Crawford, «The Asneida of Cosme de Aldana», p. 116, y «Francisco de Aldana: A Neglected Poet of the Golden Age in Spain», p. 49; Tristán Valdaspe, Curso de literatura castellana, II: Antología clásica de poetas y prosistas castellanos, F.V.D., Buenos Aires, 1939, p. 126. A pesar de lo descabellado de la proposición, hoy completamente desestimada, hay que recordar que el nombre de Francisco de Aldana se ha inscrito en el Paraninfo de la Universitat de València.

7. Francisco de Aldana, Poesías castellanas completas, ed. José Lara Garrido, Cátedra, Madrid, 1985, pp. 208-218. El soneto en italiano apareció en las Poesie toscane et latine di diversi eccelenti ingegni, Lorenzo Torrentino, Florencia, 1563, p. 97 (también se recoge en Francisco de Aldana, Epistolario poético completo, ed. Antonio Rodríguez-Moñino, Diputación Provincial de Badajoz, 1946 [reimp. facs. Turner, Madrid, 1978], pp. 31-32). Para la comedia (dedicada a «Francesco Aldana, luogotenente e figliuolo del signor Castellano della Fortezza di San Miniato» el 20 de junio de 1563), véase Girolamo Razzi, La Cecca, Lorenzo Torrentino a stanza di Giorgio Marescotti, Florencia, 1563.

8. Además de en las ediciones antiguas, el soneto A Gabriel Lasso de la Vega, criado del Rey, nuestro señor apareció tanto en Cortés valeroso y Mexicana, Pedro Madrigal, Madrid, 1588, h. $7 \mathrm{v}$, como en su segunda versión, Mexicana, Luis Sánchez a costa de Miguel Martínez, Madrid, 1594, h. 8r. En un borrador de la Bibliotheca hispana nova de Nicolás Antonio también aparece el poema (Biblioteca Nacional de España, ms. 7353, f. 119v; del tercer cuarto del siglo XvıI), 
antiguos, la mayoría dependientes de esas ediciones póstumas y todos de fecha muy tardía: la canción $A$ la soledad de Nuestra Señora, de autoría controvertida, y el Soneto al sepulcro de Nuestro Señor (Biblioteca Nacional de España, ms. 2058, ff. 138v-141r; de finales del siglo XVI o los primeros años del XVII), los sonetos "Mil veces callo, que romper deseo», «El ímpetu cruel de mi destino» y Reconocimiento de la vanidad del mundo (Biblioteca Nacional de España, ms. 2883, pp. 117-118, aunque atribuidos aquí a Bartolomé y a Lupercio Leonardo de Argensola; de 1697-1698), el Soneto a la muerte de una dama que se llamaba Lucrecia y un fragmento de La creación del mundo (Biblioteca Nacional de Espańa, ms. 3924, ff. 144v y 172v-173v; de 1582), otro testimonio del Soneto al sepulcro de Nuestro Señor (Biblioteca Nacional de España, ms. 17719, f. 235v; de 1623), los sonetos «Hase movido, dama, una pasión» y el dedicado $\mathrm{Al}$ rey Felipe, nuestro señor (Biblioteca de Bartolomé March, ms. 23/4/1, ff. 196v y 356r; de 1600), una primera redacción de las Octavas dirigidas al rey don Felipe, nuestro señor (Biblioteca Xeral de Santiago de Compostela, ms. 570; de hacia 1590-1595) y, por último, un fragmento de su composición sobre Angélica y Medoro (Biblioteca de la Universidad de Zaragoza, ms. 250-2, ff. 455r-v; c. 1628) ${ }^{9}$. Por cuanto sabemos, pues, hay muy pocas posibilidades de que la incipiente fama literaria de Francisco de Aldana pudiera haber llegado a oídos del autor de la Diana enamorada hacia los años en que la estaba escribiendo.

Pero aún habría que considerar un impedimento mayor y definitivo, y es

9. Véanse, para la datación de estos manuscritos, Cancionero de 1628, ed. José Manuel Blecua, C.S.I.C., Zaragoza, 1945; Juan Manuel Rozas, «Cancionero de Mendes Britto: poesías inéditas del Conde de Villamediana», Revista de literatura, núms. 47-48, 1963, pp. 23-100; Cancionero de Pedro de Rojas, edd. José J. Labrador Herraiz, Ralph A. DiFranco y María Teresa Cacho, Cleveland State University, Cleveland, 1988; José J. Labrador Herraiz y Ralph A. DiFranco, «El manuscrito 23/4/1 de la Biblioteca de don Bartolomé March", Bulletin Hispanique, XCIV, 1, 1992, pp. 293-325; María José Martínez López, «La primera redacción de las Octavas dirigidas a Felipe II de Francisco de Aldana y su inédita dedicatoria en prosa», Criticón, LXX, 1997, pp. 31-70. Para la datación de los mss. 2058 y 2883 (alguna vez confundido con el 269, su antigua numeración, o con el 3796) de la Biblioteca Nacional de Espańa me baso en mi propia inspección de los mismos. Mención aparte merece su poema L'Antilla, de tradición italiana; sobre él, véase el detallado estudio de María Luisa Cerrón Puga, «L’Antilla, fábula desconocida de Francisco de Aldana», Studi ispanici (1984), pp. 175-226. Deliberadamente, omito las Octavas a nuestra señora atribuidas con cierto fundamento a Juan de Herrera o a fray Luis de León pero prohijadas a Francisco de Aldana por algunos estudiosos debido a que en uno de sus textimonios se atribuyen a «un soldado Aldana», que solo el índice, posterior, identifica como Francisco de Aldana (The British Library, ms. Sloane 796, ff. 97r-v; cf. Elias L. Rivers, «A New Manuscript of a Poem Hitherto Attributed to Fray Luis de León», Hispanic Review, XX [1952], pp. 153-158), los sonetos "Cuando los ojos vuelvo a lo pasado» y «Nunca en el amor dańó atrevimiento» ¿del Conde de Vimioso? que se le atribuyeron en el siglo xvir (Biblioteca Nacional de España, ms. 17719, ff. 7r-v) y la famosa Octava a la muerte del serenisimo príncipe don Carlos (cuya atribución a Francisco de Aldana se basa en un error de interpretación sobre el que me extiendo más abajo), así como los Avisos del pastor Franco a su amigo Sebasto (Biblioteca de la Real Academia de la Historia, ms. 9/5807, ff. 81 r-94r). En este último caso, además, hay que puntualizar que, aunque la apostilla manuscrita que identificaba a Franco con Francisco de Aldana, cuando desaconsejó a don Sebastián la expedición africana, fuera correcta, nada permite suponer que fuera también el autor de esas piezas, compuestas sobre el modelo de las Coplas de Mingo Revulgo. 
que tenemos la certeza que Francisco de Aldana no era de Valencia cuando se ha demostrado hasta la saciedad que el Canto de Turia está dedicado en su integridad a personajes nacidos o residentes en ese reino. Desde luego, un vistazo a la nómina de los autores recogidos en esta composición nos permite comprobar que Gaspar Gil Polo realizó un concienzudo trabajo de historiografía literaria, para el que debió echar mano de textos que no se habían publicado -y que en su época solo se conservaban manuscritos- con el único objeto de dignificar la tradición lírica local, ya en catalán, ya en castellano, y completar su elenco de autores ${ }^{10}$, y las últimas investigaciones han venido a confirmar que, en efecto, hasta aquellos poetas allí aludidos de los que hasta hace poco no se sabía absolutamente nada (sería el caso de Martí Garcia, por ejemplo), eran valencianos ${ }^{11}$.

Llegados a este punto, no puede sino sorprender que a estas alturas y con todos esos elementos en contra todavía se repita cansinamente el cliché de que el autor elogiado al final del Canto de Turia es Francisco de Aldana. Y sorprende, sobre todo, cuando su supuesta inclusión en ese elenco de poetas valencianos ya había despertado anteriormente el recelo de algunos investigadores aunque, a pesar de ello, seguían aceptándolo: "Gil Polo, creyéndole, no sé por qué, valenciano, había de informarnos de él en su Canto del Turia», escribía José María de Cossío a la hora de presentar La fábula de Faetonte; "el valenciano Gaspar Gil Polo, que creía también valenciano a Aldana, lo elogiaba en su Diana enamorada», "pero no es valenciano y sólo contaba entonces veintitrés años» advertían respectivamente Ricardo Senabre y Francisco López Estrada cuando explicaban la supuesta fama juvenil de este poeta ${ }^{12}$. No había nada, pues, que discutir. Era más fácil, desde luego, achacarlo todo a una burda equivocación de Gaspar Gil Polo, echando por tierra toda su laboriosa investigación literaria en las bibliotecas valencianas y haciéndole quedar como un completo ignorante de la poesía y los poetas de su ciudad y su época o, lo que es peor, como un mentiroso redomado que pretendió engrandecer la gloria literaria de Valencia prohijando a esta ciudad un autor de fama indiscutible. Es, en fin, una excelente muestra de hasta qué punto la simple repetición mimética y la falta de revisiones críticas y constructivas se ha enquistado en la mayoría de los campos de la investigación literaria española.

10. Muy atinadas al respecto me parecen las observaciones de Pep Valsalobre, «Una cort "ferraresa" a València: els Centelles, Ariosto i un programa de substitució de la tradició literària autòctona", Caplletra, XXXIV (2003), pp. 171-194.

11. Lo demuestra cumplidamente Jaume Torró, Sis poetes del regnat d'Alfons el Magnànim, Barcino, Barcelona, 2009, p. 126.

12. José María de Cossío, Fábulas mitológicas en España, p. 196; Ricardo Senabre, Escritores de Extremadura, p. 47; Francisco López Estrada, ed., Gaspar Gil Polo, Diana enamorada, p. 227. También Elias L. Rivers mostraba sus dudas, y suponía que Gaspar Gil Polo había confundido al capitán Francisco de Aldana con el también militar Juan Aldana, quien sí vivió en Valencia; sin embargo, no dudaba que quién era el personaje al que se quería elogiar («Francisco de Aldana, el divino Capitán», p. 454). A todos los superaba, sin embargo, Alfredo Lefebvre, quien al calificar el encendido elogio remarcaba su «fuerte deje provinciano» (La poesía del capitán Aldana, p. 66). 
Resulta evidente, pues, que ante la absoluta imposibilidad de que Francisco de Aldana, "el divino», sea el poeta elogiado en el tercer libro de la Diana enamorada, hay que identificar «un nuevo Aldana», militar y poeta ligado a la ciudad de Valencia, perfecto conocedor de la lengua italiana, que viviera a mediados del siglo XVI y que gozara de una cierta fama literaria entre sus vecinos. Y, por supuesto, de inmediato aparece un candidato que reúne todos esos requisitos, aunque no aparezca en ninguno de los manuales de historia de la literatura: Marco Antonio Aldana.

Una rama de la familia Aldana, oriunda de Tortosa, se asentó en Valencia en el segundo cuarto del siglo xvi. Se trataba de los descendientes de Juan Aldana, un capitán de Fernando el Católico y Carlos I de oscuros orígenes que se distinguió en las campañas de Francia e Italia ${ }^{13}$. Tomó parte en la batalla de Salses (1503), la expedición de los Gelves (1520), la batalla de Bicoca (1521) y, sobre todo, en la batalla de Pavía (1525), donde hizo prisionero a Francisco I, arrebatándole el collar de la Orden de San Miguel, la espada, la daga y un riquísimo libro de horas. En 1526 fue llamado a Valencia por su virrey Fernando de Aragón, duque de Calabria, quien le encomendó el mando de las operaciones contra los moriscos amotinados en la Sierra de Espadán. Poco después, junto a Joan Cervelló, se le encargó el refuerzo y la reforma de las murallas de Alicante y Villajoyosa. El punto culminante de su carrera militar llegó en Túnez, cuando Carlos I lo armó caballero el 20 de julio de 1535. En 1527 había contraído matrimonio, en Tortosa, con Magdalena Amic, y de esa unión nacieron seis hijos: Marco Antonio, Julio César, Mateo Aníbal, Juana Magdalena, Magdalena Leonor y Quinto Sertorio. Julio César abrazó la carrera eclesiástica, obtuvo el grado de doctor en leyes y fue capellán de Felipe II. Mateo Aníbal también siguió la carrera de las armas y participó en las campañas de los Gelves (1560) y Perpiñán (1570); en 1569 se casó con Anna Vicenta Despuig i Curto (hija del escritor Cristòfol Despuig) y disfrutó de una vida tranquila, gozando de las rentas y posesiones familiares en Tortosa. Aunque fue el único que contrajo matrimonio, no tuvo descendencia. Juana Magdalena debió morir siendo muy niña, quizá antes de cumplir su primer año. Magdalena Leonor profesó en 1554 en el convento de Santa María Magdalena de Valencia, de la Orden de Santo Domingo, y en 1587 le fue permitido un traslado al monasterio de Santa María de la Rápita, de la Orden de San Juan, del cual fue

13. A finales del siglo xvi corría por Tortosa el rumor de que Juan Aldana era, en realidad, hijo del notario Miquel Sabater y de una hija (o nieta, dependiendo del informante) de una mujer presa en la cárcel de la Inquisición del Obispado de Tortosa, Francina Massip, más conocida como "Cassoletes», procesada en 1489. Al morir, el padre lo habría encomendado al también notario Juan Aldana, de quien habría tomado el nombre. En la Relación de los sanbenitos de Tortosa se detalla el que corresponde a Francina Massip «mujer de Francisco Massip, vecino de Tortosa, relajada por la ley de Moysén, año mCCCCLXXXviıI». El malicioso cotilleo lo refirieron el notario Joan Puigvert y mossèn Jaume Cerverò, respectivamente canónigo de Tortosa y arcediano de Corbera, al inquisidor Juan de Guzmán, cuando este requirió información sobre los orígenes de esos sambenitos y sus descendientes (Tortosa, 21-x-1577; Archivo Histórico Nacional, Inquisición, leg. 598/2, [carpetilla sin numerar y sin foliar], ff. [3r], [11v-12r] y [15r-v]). 
priora. Quinto Sertorio murió joven, en la expedición de los Gelves. Todos ellos vivieron a caballo entre Tortosa, de donde procedían, y Valencia, donde se habían establecido ya en 1542. En atención a los servicios prestados por Juan Aldana, Felipe II protegió especialmente a esta familia. Por medio de sendas reales órdenes, en 1556 concedió una pensión vitalicia de cien escudos a Marco Antonio, Quinto Sertorio y Mateo Aníbal; el hermano restante, Julio César, fue nombrado en 1566 regente del castillo de Capua, en el reino de Nápoles ${ }^{14}$. El

14. Para todo ello, véase Rafael Martí de Viciana, Segunda parte de la Crónica de Valencia (1564), ed. José María Torres, Sociedad Valenciana de Bibliófilos, Valencia, 1881 [reimp. facs. Librerías París-Valencia, Valencia, 1980], pp. 54-55; Francisco Martorell y de Luna, Historia de la antigua Hibera (1626), ed. Joan Abril Guanyabens, Josep L. Foguet para el diario La Veu de la Comarca, Tortosa, 1925, pp. 85-86 y 206-218; Juan Francisco Andrés de Uztarroz, Segunda parte de los Anales de Aragón, Herederos de Pedro Lanaja, Zaragoza, 1663, p. 104; Federico Pastor y Lluís, Narraciones tortosinas, Imprenta de Josep L. Foguet y Sales, Tortosa, 1901, pp. 237241; Manuel Beguer Pinyol, El Real Monasterio de Santa María de la Rápita, de la sagrada y soberana milicia hospitalaria de San Juan de Jerusalén (Orden de Malta), Algueró y Baiges, Tortosa, 1948, pp. 77, 83-92 y 97-98; Enrique Bayerri y Bertomeu, Historia de Tortosa y su comarca, VIII, Algueró y Baiges, Tortosa, 1959, p. 654; María Soledad Carrasco Urgoiti, El problema morisco en Aragón al comienzo del reinado de Felipe II, University of North Carolina, Chapel Hill, 1969, p. 102; Manuel Beguer i Pinyol, Llinatges tortosins, Dertosa, Tortosa, 1980, pp. 35-48; Joan-Hilari Muñoz i Sebastià y Salvador J. Rovira i Gómez, Tortosa en temps de Carles I, segons els Llibres de Rúbriques, Ajuntament de Tortosa, 2000, pp. 46, 48 y 50; Salvador J. Rovira i Gómez, Els nobles de Tortosa: segle XVI, Consell Comarcal del Baix Ebre, Tortosa, 1996, pp. 153155 y 308; Carlos José Hernando Sánchez, Castilla y Nápoles en el siglo XVI. El virrey Pedro de Toledo: Linaje, estado y cultura (1532-1553), Junta de Castilla y León. Consejería de Cultura y Turismo-Valladolid, 1994, p. 169; Colección de documentos inéditos para la historia de España, V, edd. Martín Fernández de Navarrete, Miguel Salvá y Pedro Sainz de Baranda, Real Academia de la Historia-Imprenta de la Viuda de Calero, Madrid, 1844, pp. 88-91. Añádanse a esas fuentes impresas los siguientes documentos: Génova, 1-II-1525: Carta de Lope de Soria a Carlos I en la que le comunica la llegada del Capitán Aldana con refuerzos la víspera de la batalla de Pavía (Biblioteca Nacional de España, ms. 20.214/62/6). Campo de Túnez, 20-viI-1535: Carlos I ordena caballero a Juan Aldana y hace una detallada relación de sus méritos militares (Real Academia de la Historia, Comisión de Antigüedades de Tarragona, 9/7975/59 [3], ff. 2-19). Bruselas, 20-vI-1556 y 13-vIII-1556: Felipe II ordena que los hermanos Marco Antonio, Quinto Sertorio y Mateo Aníbal Aldana reciban una pensión anual de cien escudos, que procederán de los fondos de los reinos de Valencia, Nápoles y Sicilia respectivamente (Real Academia de la Historia, Comisión de Antigüedades de Tarragona, 9/7975/59 [3], ff. 33-41). Madrid, 15XI-1566: Felipe II provee al doctor César Aldana, su capellán, de una regencia de las dos que ha creado para el castillo de Capua (Real Academia de la Historia, Comisión de Antigüedades de Tarragona, 9/7975/59 [3], ff. 42-46). Madrid, 28-IX-1649: El Consejo de Aragón suplica a Felipe IV que conceda una pensión alimenticia de 200 reales al mes a Jusepa Antic Carrades de Voltor, heredera de los bienes y rentas de la familia Aldana, como compensación por la ruina de su hacienda tras la pérdida de Tortosa; en el memorial en que se solicitaba esa ayuda se mencionaban los privilegios anteriores concedidos por Carlos I y Felipe II, certificados por el Obispo de Tortosa (Archivo de la Corona de Aragón, Consejo de Aragón, leg. 301, núm. 73). Como nota curiosa, cabe añadir que la media armadura conservada en la Real Armería, y que durante mucho tiempo se consideró que había pertenecido a Juan Aldana (Catálogo de la Real Armería, Aguado, Madrid, 1849, núm. 1231), en realidad parece haber pertenecido, más bien, a Carlos I. Fuera como fuere, Juan Aldana debió disfrutar en su época de fama de de militar valiente y esforzado, pues lo recuerdan autores como Baldassare Castiglione (Il libro del Cortegiano, edd. 
árbol genealógico reconstruido hasta el momento resulta como sigue:

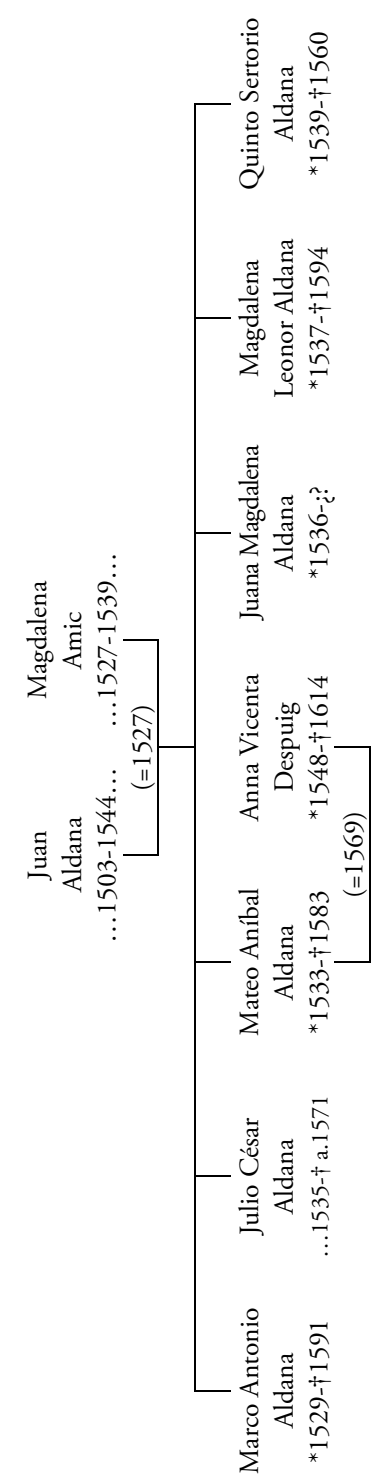

Amedeo Quondam y Nicola Longo, Garzanti, Milán, 1981, p. 230) o Eustaquio Celebrino (La presa di Roma, recogido en Ana Vián Herrero, El «Diálogo de Lactancio y un Arcidiano» de Alfonso de Valdés: obra de circunstancias y diálogo literario. Roma en el banquillo de Dios, Anejos de Criticón 3, Presses Universitaires du Mirail, Toulouse, 1994, p. 185). 
Marco Antonio Aldana, el hermano mayor, que es quien realmente nos interesa, fue bautizado el 28 de abril de 1529. Sentó plaza de soldado, primero a las órdenes de su padre y más tarde en la defensa de Nápoles y Sicilia contra los turcos, en la que se distinguió especialmente. A su regreso se convirtió en el portavoz oficial de la familia para todos los asuntos relacionados con Valencia. Hacia esos mismos años entró al servicio de Diego Fernández de Córdoba el Africano, V duque (consorte) de Cardona y III marqués de Comares. En su vejez, fallecidos sus hermanos varones, regresó a Tortosa. Con ocasión del paso de Felipe II por esa ciudad, en 1585, le regaló la espada y la daga que su padre, Juan Aldana, había arrebatado a Francisco I. Como recompensa, fue beneficiado con una renta de doscientos ducados anuales sobre la bailía de Valencia. Otorgó testamento en Falset, el 14 de octubre de 1583, que se hizo público el 22 de enero de 1591, por lo que podemos suponer que falleció poco antes $^{15}$.

De su afición a las letras, desde luego, no se puede dudar. Muestra excelente de ello es el hermoso epigrama que le dedicó el poeta neolatino Domingo Andrés entre 1573 y 1575: Ad Marcum Antonivm Aldanam, cvm, me abevnte, variis ipse rervm studiis, honestis animi relaxationibvs, Dertvsa deleniretvr. Además de los consabidos elogios debidos a un caballero, alabando su prudente justicia y su valor guerrero («Est etiam in legum studiis tibi quanta uoluptas! | Es quoque, si incessant prœlia, quantus eques!», vv. 29-30), relata cómo al escuchar sus composiciones «sed cohibet cursum flumen et aura silet; | nec lepidos uates oratoresque seueros | abiicis: hi faciunt otia gratia tibi» (vv. 2426). De esa manera, a lo largo de sus versos se complace en resaltar cómo su amigo de juventud reparte el ocio entre las obligaciones sociales, el estudio y la poesía "Mercurio solis et cognite Musis» (v. 4) ${ }^{16}$. Sus aficiones literarias, sin embargo, no debían ser tan secretas como estas afirmaciones de Domingo Andrés permiten suponer, pues en 1584 Antonio Folc de Cardona-Anglesola

15. Añádase a las referencias anteriores Enric Querol Coll, Estudis sobre cultura literària a Tortosa a l'Edat Moderna, Publicacions de l'Abadia de Montserrat, Barcelona, 2006, pp. 123-124 y, sobre todo, «Els Aldana, tortosins del xvi aveïnats a València: de les armes a les lletres», Pedralbes. Revista d'història moderna, XXVII (2007), pp. 199-218 (importante artículo aparecido cuando este trabajo estaba a punto de finalizar); Colección de documentos inéditos para la historia de España, XXXVIII, edd. Marqués de Pidal, Marqués de Miraflores y Miguel Salvá, Real Academia de la Historia-Imprenta de la Viuda de Calero, Madrid, 1861, pp. 557-561, así como los siguientes documentos: Valencia, 7-I-1564: Marco Antonio Aldana, portavoz de Cristòfol Despuig, presenta al inquisidor Alonso de Sotomayor un memorial en el que acusa a los funcionarios del Santo Oficio de Tortosa de causarle diferentes agravios, participar en bandosidades y otros delitos (Archivo Histórico Nacional, Inquisición, leg. 519/2, núm. 23). San Lorenzo del Escorial, 1-vII1589: Felipe II ordena que Marco Antonio Aldana reciba anualmente 200 libras, procedentes de la bailía de Valencia; por ese documento, además, sabemos que anteriormente se le había otorgado una renta anual de 200 ducados procedentes de las rentas del reino de Nápoles, que esta nueva donación viene a sustituir (Arxiu del Regne de València, reg. 363, ff. 34-36; Real Academia de la Historia, Comisión de Antigüedades de Tarragona, 9/7975/59 [3], ff. 20-32).

16. José María Maestre, Poesías varias del alcañizano Domingo Andrés, Instituto de Estudios Turolenses, Teruel, 1987, pp. 172-176. 
y Fernández de Córdoba, V duque de Sessa, de Terranova y Santángelo, IV duque de Somma y III duque de Baena, propuso su nombre al Consejo de la Inquisición como el candidato ideal para realizar una traducción correcta, aunque convenientemente expurgada, de las obras políticas de Maquiavelo. Posiblemente habría que buscar el origen de esta recomendación en el hecho de que el padre de don Antonio, don Fernando Folc de Cardona-Anglesola y Requesens, II duque de Somma, III conde de Palamós, Trivento y Avellino y II conde de Oliveto, había ostentado la dignidad de Gran Almirante y Capitán General del Mar del Reino de Nápoles, donde es muy probable que tanto Marco Antonio Aldana como sus hermanos hubieran servido bajo sus órdenes. Además, no hay que olvidar que el V Duque de Sessa era yerno del V Duque consorte de Cardona (se había casado con la hija de este, Juana de Córdoba y Aragón, en 1578), al servicio del cual, como ya se ha señalado, figuraba Marco Antonio Aldana.

La carta merece copiarse por completo, pues proporciona algunas noticias interesantes sobre la formación y las aficiones culturales de Marco Antonio Aldana:

\section{Ilustrísimo y Reverendísimo:}

Muchos hombres principales y de calidad sienten la falta de las obras de Nicholao Machiavelo que se ha prohibido por el nuevo Índice y catálogo que se ha publicado, y particularmente los libros que intitula De discursos, Príncipe, Diálogos del arte de la guerra y Historias de la república de Florencia, dirigidas a la buena memoria de León décimo, por tratar en los dichos libros materias de estado y gobierno en tiempo de paz y guerra con mucha curiosidad y erudición. $\mathrm{Y}$ aunque en ellas hay algunos errores y cosas impías y malsonantes, hay otras de mucha curiosidad y aprovechamiento; y las que no son tales se pueden fácilmente expurgar, enmendar y corregir, y aun traducirse los dichos libros de lengua italiana en vulgar castellana y imprimirse con nombre de otro autor, no conviniendo que anden en el del dicho Nicholao Machiavelo.

Todo lo cual se ofrece hará a su costa el Duque de Sesa y Soma, por entender de la utilidad que son y pueden ser los dichos libros. Y corregidos y enmendados, de suerte que no tengan error ni sospecha dél, ni cosa que pueda ofender a ningún fiel y católico cristiano, los remitirá a Vuestra Señoría Ilustrísima Reverendísima y al Supremo Consejo de la Santa y General Inquisición para que, vistos en él, y que no tienen en qué se haya de reparar, se pueda mandar traducir y imprimir. Y para la versión de la lengua italiana en vulgar castellana, y para que en su nombre se imprima y publique, le parece será muy a propósito don Marco Antonio de Aldana, hijo del coronel Aldana, por ser muy gran latino y italiano, y muy cortado en hablar la lengua espańola y saber también muchas cosas de las que trata dicho Machiavello y tener práctica y noticia della; o otro que a Vuestra Ilustrísima Señoría mejor pareciere.

A Vuestra Ilustrísima Señoría Reverendísima suplica el Duque que mande que esto se provea y haga así, que serán de mucha utilidad y provecho las dichas obras para personas de calidad y curiosas de saber semejantes materias.

En efecto, el año anterior el Índice del Inquisidor General Gaspar de Quiroga, siguiendo las indicaciones de Pablo IV y Pío IV, había incluido todas las obras 
de Maquiavelo entre los libros prohibidos ${ }^{17}$. Más allá de las implicaciones políticas y religiosas de este dato, y de la perspicacia mostrada por el V Duque de Sessa al intentar que al menos la parte más útil de esos textos pudiera ser accesible a los lectores españoles, en este caso es importante incidir en el hecho de que el personaje propuesto para llevar a cabo esa labor fuera Marco Antonio Aldana. Por un lado, la súplica nos informa de su pericia en el uso del latín y el italiano (recuérdense, a tal efecto, los versos con que unos años antes había sido elogiado en el Canto de Turia: «en gran duda pondrán si él es Petrarca, | o si Petrarca es él»). Junto a ese dominio de las lenguas extranjeras, también se destaca una cierta soltura literaria (al fin y al cabo, se le califica como «muy cortado en hablar la lengua espańola»). Y, por último, se destacan unas aptitudes personales que lo acreditan como el mejor traductor posible: como soldado y como buen conocedor del derecho (las mismas cualidades que había destacado Domingo Andrés), domina perfectamente la materia tratada en esos libros. Y no la conoce únicamente por sus lecturas, sino que se especifica expresamente que tiene "práctica y noticia» de las mismas.

La solicitud consta como recibida "En Madrid, a 9 de noviembre de 1584», y en el margen se anotó la decisión tomada: «Que se exhiban en el Consejo los libros que aquí se refieren». Acatando esa orden, unos meses más tarde el V Duque de Sessa insistía en su petición ante la Suprema. Otra vez se proponía a Marco Antonio Aldana para realizar el trabajo, si bien en esta ocasión también se ofrecía la opción de que lo realizara Juan Bautista de Cardona, entonces obispo de Vic, quien gozaba hacia esos años de un gran renombre como erudito:

\section{Ilustrísimo y Reverendísimo:}

Muchos días ha que el Duque de Sesa y Soma suplicó a Vuestra Señoría Ilustrísima Reverendísima fuese servido proveer y mandar cómo los Discursos y el libro intitulado Principe, Diálogo del arte de la guerra y Historias de la república de Florencia, dirigido a la buena memoria de León décimo, y compuestos por Nicolao Machiavelo se enmendasen, por ser de mucho provecho y utilidad para personas curiosas; y aun, siendo Vuestra Señoría Ilustrísima Reverendísima servido, se tradujesen de lengua italiana en vulgar castellana. Y ofreció que este trabajo de enmendarlas y traducirlas lo haría Marco Antonio Aldana o el doctor Cardona, obispo de Vique; y hecho, antes de se imprimir se trairían ante Vuestra Señoría Ilustrísima Reverendísima y su Consejo de la Sancta y General Inquisición. Y se ofreció que la costa que en esto se hiciese la pagaría de muy buena voluntad, por la utilidad de dichos libros

Vuestra Señoría Ilustrísima Reverendísima proveyó y mandó que se presentasen ante Vuestra Señoría Ilustrísima los dichos libros, los cuales exhibe; y de nuevo torna a suplicar a Vuestra Señoría Ilustrísima Reverendísima le haga merced de mandar que

17. Index et cathalogus librorum prohibitorum, Alphonsum Gomezium, Madrid, 1583, ff. 51r, 65v y 75r. Cabe recordar, sin embargo que ya anteriormente había aparecido la prohibición expresa de toda su obra en los índices que había elaborado la curia romana: Index auctorum et librorum, Antonium Bladium, Roma, 1559, f. 25v; Index librorum prohibitorum, Paulum Manutium, Roma, 1564, p. 61. La prohibición papal de la lectura de todas las obras de Maquiavelo, de hecho, se produjo el 5 de julio de 1558 (Ricardo García Cárcel, Herejía y sociedad en el siglo XVI: La Inquisición en Valencia 1530-1609, Península, Barcelona, 1980, p. 51). 
el dicho Obispo de Vique los corrija y enmiende y traduzga de lengua italiana en castellana. Y hecho esto, los torne a remitir a Vuestra Señoría Ilustrísima Reverendísima para que mande se impriman debajo del nombre de otro autor cual Vuestra Señoría Ilustrísima Reverendísima fuere servido, que en ello el Duque le recibirá muy grande, y todos los curiosos que se pretenden aprovechar de los dichos libros ${ }^{18}$.

Esta vez la solicitud consta como recibida «En Madrid, a primero de junio de 1585», y en el margen se consignó la decisión final de la Suprema: "Fiat. Su Señoría Ilustrísima», quien otorgó la correspondiente autorización ${ }^{19}$. Aunque, por cuanto se sabe, el proyecto fue finalmente desatendido, las dotes políticas apuntadas por el V Duque de Sessa hacia esos años -y de la que estas cartas son una excelente muestra- resultaron tan evidentes que Felipe II lo nombró embajador en la Santa Sede, cargo que ostentó entre 1592 y 1605 en sustitución de don Enrique de Guzmán, II conde de Olivares, quien había comprometido muy seriamente las relaciones entre España y Roma ${ }^{20}$. Más allá de lo que supone, sin embargo, todo este episodio perfila la figura de don Antonio Folc de Cardona-Anglesola y Fernández de Córdoba como la de un peculiar protector de las letras, sobre todo en cuanto contribuyeran a mejorar la sociedad ${ }^{21}$. Desde luego, no deja de ser significativo que, en esa ocasión,

18. Archivo Histórico Nacional, Inquisición, leg. 4436/1, núm. 4. Véanse, sobre estas cartas, Giovanni M. Bertini, «La fortuna di Machiavelli in Spagna», Quaderni ibero-americani, núm. 2 (1946), pp. 21-22 y 25-26, José Antonio Maravall, «Maquiavelo y maquiavelismo en España», Boletín de la Real Academia de la Historia, CLXV (1969), pp. 183-218 (recogido en Estudios de historia del pensamiento español. Serie Tercera: El siglo del Barroco, Ediciones Cultura Hispánica del Instituto de Cooperación Iberoamericana, Madrid, 1984², pp. 39-72 [en concreto, 48-49]), Elena Puigdoménech, «Maquiavelo, la Monarquía y la Inquisición española», Boletín de la Real Academia de Buenas Letras de Barcelona, XXXVI (1975-1976), pp. 203-210, y Virgilio Pinto Crespo, «Nuevas perspectivas sobre el contenido de los índices inquisitoriales hispanos del siglo XvI», Hispania Sacra, XXXIII (1981), pp. 593-641 (en concreto, 632-633).

19. «Obispo de Vich: que pueda traducir ciertos libros de lengua italiana en castellana. En la villa de Madrid, a primero día del mes de junio del mil e quinientos y ochenta y cinco ańos. El Ilustrísimo Señor don Gaspar de Quiroga, cardenal de Toledo, Inquisidor General en los reinos e señoríos de Su Majestad, estando en el Consejo de la Santa General Inquisición, dio licencia para que el Ilustrísimo Señor don Juan Baptista de Cardona, obispo de Vich, pueda traducir y traduzga de lengua italana [sic, escrito sobre catalana] en castellana el libro de los Discursos y el intitulado Principe, Diálogo de arte de la guerra y Historias de la república de Florencia, dirigidos a la buena memoria de León décimo, y compuestos por Nicolao Machiavelo, quitando dellos todas las cosas que le paresciere no se deben permitir. Y, hecha la dicha tradución y correctión, antes que se imprima se traiga al dicho Consejo juntamente con los libros originales para que, todo visto, se provea lo que convenga. Ante mí, Pablo García, secretario del dicho Consejo. Pablo García» (Archivo Histórico Nacional, Inquisición, leg. 357, ff. 113r-v).

20. Véanse las opiniones que, sobre su papel como embajador, expresan Gregorio Marañón, El Conde-Duque de Olivares (La pasión de mandar), Espasa-Calpe, Madrid, 19726, pp. 14-17 y John H. Elliott, El Conde-Duque de Olivares. El político en una época de decadencia, Crítica, Barcelona, 1998, p. 29.

21. A iniciativa suya, por ejemplo, se escribió la Microcosmia y gobierno universal del hombre cristiano de fray Marco Antonio Camós (Pablo Malo, Barcelona, 1592), aunque hay que recordar que en un primer momento le había propuesto su redacción a fray Luis de León quien, ya muy mayor, no pudo complacerle (Agustín G. de Amezúa, Lope de Vega en sus cartas, I, 
presentara a Marco Antonio Aldana como la persona que mejor podía realizar el trabajo, sobre todo si se considera que, a su lado, proponía a Juan Bautista de Cardona, uno de los más destacados intelectuales del reinado de Felipe II $^{22}$.

Dejando ahora a un lado esas noticias puntuales sobre su actividad literaria, resulta significativa su aparición en un listado delos principales poetas valencianos del tercer cuarto del siglo xvi. Me refiero al romance «Ya cabalga Dios Cupido | a Venus besar la mano» (formulado en sus primeros versos, claro, sobre el conocido "Ya cabalga Diego Laínez | al buen rey besar la mano»), incluido por Joan Timoneda en su Rosa de amores de 1573 pero que muy posiblemente se había publicado anteriormente en la primera parte, hoy perdida, de su Sarao de amor de 1561. Ahí, al pasar revista a los grandes escritores de Valencia que salen a agasajar al dios del amor y a su séquito de poetas clásicos y medievales, no podía faltar Marco Antonio Aldana:

A rescebirle han salido
en un fresco y verde llano
don Gaspar de Romaní,
don Manuel Fernando, humano,
don Alonso Rebolledo,
mancebo en saber muy cano,
ese don Luis de Milán,
a la música cercano,
Marco Antonio y Pellicer,
Samper, discreto y anciano,
Gil Polo, Espinosa, Pérez,
con Arcayna, ciudadano,
Almodévar, Timoneda,
de poesía comarcano ${ }^{23}$.

Muy significativo, desde luego, es que «Marco Antonio» aparezca en compañía de Gaspar Gil Polo, así como de Gaspar de Romaní, Manuel Fernando, Alonso

[Real] Academia Española-Tipografía de Archivos, Madrid, 1935, pp. 10-11; y, sobre la obra, Francisco Rico, El pequeño mundo del hombre. Varia fortuna de una idea en la cultura española, Destino, Barcelona, 2005, pp. 168-170). Dejo para otra ocasión el comentario de su interesante producción poética.

22. De Juan Bautista de Cardona, obispo de Vic (1584-1587) y Tortosa (1587-1589), así como de su fama en España e Italia, dan abundantes noticias Félix Torres Amat, Memorias para ayudar a formar un diccionario crítico de los escritores catalanes, J. Verdaguer, Barcelona, 1836, p. 175, y Marcelino Menéndez y Pelayo, Estudios y discursos de crítica histórica y literaria, ed. Enrique Sánchez Reyes, IV, Consejo Superior de Investigaciones Científicas, Madrid, 1942, p. 77; Biblioteca de traductores españoles, ed. Enrique Sánchez Reyes, IV, Consejo Superior de Investigaciones Científicas, Madrid, 1953, p. 292, y La ciencia española, ed. Enrique Sánchez Reyes, III, Consejo Superior de Investigaciones Científicas, Madrid, 1954, pp. 104 y 138.

23. Rosas de romances por Joan Timoneda (Valencia, 1573), edd. Antonio Rodríguez-Moñino y Daniel Devoto, Castalia, Valencia, 1963, f. 2v (de la Rosa de amores). Sobre los problemas bibliográficos de esa perdida primera parte del Sarao de amor, impresa en 1561, véanse Antonio Rodríguez-Moñino, ed., Juan Timoneda, Cancioneros llamados "Enredo de amor», "Guisadillo de amor» $y$ «El truhanesco», Castalia, Valencia, 1951, pp. 13-24, y Carlos Clavería, ed., Cancionero llamado «Sarao de amor» compuesto por Juan Timoneda, Delstre’s, Barcelona, 1993. 
Girón de Rebolledo, Luis de Milán, Cristóbal Pellicer, Jerónimo Sempere, Nicolás Espinosa, Juan Bautista Pérez y Onofre Almodévar, quienes también tendrían su correspondiente elogio en el Canto de Turia unos pocos años después ${ }^{24}$.

A pesar de todas las indicaciones de las páginas precedentes, hay que reconocer que la obra poética de Marco Antonio Aldana descubierta hasta el momento es muy escasa y se encuentra, además, dispersa por los diferentes libros de quienes debieron ser sus compañeros en sus ocios poéticos. También resulta significativo que solo el primero de los poemas se publicara en torno a la fecha del Canto de Turia; los otros aparecen póstumamente. Todo denota que se trata de piezas escritas con anterioridad, en su etapa valenciana. Y aunque puede parecer extraño que un poeta de obra tan exigua -cuando menos, la parte descubierta hasta ahora- mereciera tantos elogios de sus contemporáneos, la verdad es que esa suele ser la tónica general en estos casos. Se trataba de autores cuya producción corría sobre todo en manuscritos y cuya fama literaria se reducía a un círculo de amigos y a un marco geográfico muy limitado ${ }^{25}$. A pesar de esas limitaciones, he decidido recogerla aquí, para que el lector tenga una impresión, siquiera superficial, del talento lírico que se complació en destacar Gaspar Gil Polo, hasta el punto de calificarlo como «aquel que con extraño espanto | al mundo ha de causar naturaleza» y de cerrar con él, y las tres lapidarias octavas dedicadas a su extraordinario quehacer poético, el célebre Canto de Turia. Vista desde nuestra época, tal apreciación parece, cuando menos, un poco exagerada, a pesar de que se observan, también, algunos aciertos de innegable interés. Quizá con el tiempo aparezcan nuevas composiciones que la vengan a confirmar de forma más explícita.

\title{
De Marco Antonio Aldana \\ Soneto
}

\author{
Callen de hoy más los griegos y romanos \\ de su Alejandro y César las hazañas, \\ y del que abrió con fuego las montañas \\ no curen de hablar más los africanos; \\ alaben los triünfos soberanos \\ de Carlo invicto, rey de las Españas, \\ con las vecinas gentes, las estrañas,
}

\footnotetext{
24. Es importante señalar que la identificación de este «Marco Antonio» con Marco Antonio Aldana no solo se sustenta en su actividad poética, sino en que en esta ocasión también coinciden el círculo literario, la ciudad y la época. Por eso, a la hora de hablar de su obra, se ha prescindido de otros «Marco Antonio» poetas localizados a lo largo la segunda mitad del siglo XvI, como Marco Antonio de la Vega, a quien sus contemporáneos se referían a menudo solo por su nombre de pila, como demuestran el Cancionero general de la doctrina cristiana hecho por Juan López de Úbeda [1579. 1585, 1586], ed. Antonio Rodríguez-Moñino, II, Sociedad de bibliófilos españoles, 1964, pp. 16-17 y 51, o Lucas Rodríguez, Romancero historiado [Alcalá, 1582], ed. Antonio Rodríguez Moñino, Castalia, Madrid, 1967, p. 212.

25. Confieso mi deuda con el soberbio trabajo de Antonio Rodríguez-Moñino, Construcción crítica y realidad histórica en la poesía española de los siglo XVI y XVII, Castalia, Madrid, 1968.
} 
que fueron debeladas por sus manos.

Tan heroicos hechos, y cantados con tan heroico estilo, nunca vido ni la pasada edad ni la moderna.

Estos lauros a España eran guardados, que su nación el mundo haya vencido y que Samper su fama hiciese eterna.

Jerónimo Sempere, Primera [y segunda] parte de la Carolea, Juan de Arcos, Valencia, 1560, f. [150]r.

\section{Mar[c]o Antonio Aldana, caballero valenciano, en conmemoración de la obra}

Aquel tirano que, al mayor planeta siguiendo siempre con ligero vuelo, pone a los grandes hechos negro vel[o] y hace la obra más clara más se[c]re[t]a, el que con negra pez tińe y sujeta la diosa que se opone al mortal hielo y hace vivir de nuevo acá en el suelo a los pasados que la tierra aprieta de las doradas islas la memoria y todo el baleárico estallido había vuelto en silencio y en escoria cuando el gran Binimelis, con su historia, los saca del profundo del olvido y les da nueva vida, fama y gloria.

Juan Binimelis, Nueva historia de la isla de Mallorca, s.e., I, Imprenta de José Tous para el diario La última hora, Palma de Mallorca, 1927, p. XviII. El original catalán se redactó hacia 1590-1595 y la traducción al español (en la que se recogen los poemas preliminares) se realizó hacia 1601. Se conservan varios testimonios manuscritos de esta traducción, datables en los siglos XVII-XIX: Biblioteca de la Societat Arqueològica Lul.liana (mss. 2348-2351); Biblioteca Lambert Mata de Ripoll (ms. 102); Biblioteca del Monestir de Montserrat (mss. 476-480); The British Library (mss, Add. 24911-24912); el más antiguo, posiblemente autógrafo (Biblioteca Nacional de España, ms. 10344), solo contiene los últimos tres libros.

\section{Soneto de don Marcantonio Aldana al autor}

Oh tú, que con la pluma y con la espada, con mucha más ventaja que otros hombres en diferente profesión y nombres, muestras tu altiva frente laureada;

tú, a quien Marte le dio timbre y celada para que armado al enemigo asombres, y Apolo, el dulce título y renombres 
con que a las ninfas del Parnaso agrada;

loarte yo es hacerte grande injuria, que quien con tanta luz al mundo sale poético raudal requiere, y furia.

$\mathrm{Y}$ así, porque al sujeto en parte iguale, será bueno lo mande al sacro Turia Valencia, que por ser tu patria vale.

[Andrés Rey de Artieda], Discursos, epistolas y epigramas de Artemidoro, Ángelo Tavanno, Zaragoza, 1605, h. 4r. Octava a la muerte del serenísimo príncipe don Carlos,
del único Aldana

Nací de agüelo y padre sin segundo, de tantos reinos príncipe heredero; henchí de miedo y esperanza el mundo, joven ardiente y de ánimo guerrero. Muerte en punto derribó al profundo las esperanzas de tan alto agüero.

¡Ah, suerte humana! ¿Quién en ti confía? Ayer fui Carlos de Austria, hoy tierra fría.

Ibidem, ff. 29v-30r.

Este último poema merece un comentario detenido. Por una parte, el hecho de que en el epígrafe se atribuya al «único Aldana» ha llevado a algunos estudiosos a prohijar la octava a Francisco de Aldana, sin advertir que en los folios preliminares del mismo libro aparecía un soneto de Marco Antonio Aldana ${ }^{26}$. Desde luego, habría sido una desconsideración imperdonable que Andrés Rey de Artieda opinara lo mismo, sobre todo con alguien que había sido su compañero en las aficiones poéticas cuarenta años atrás (cuando ambos habían sido elogiados en el Canto de Turia), que había compuesto un soneto en su honor y que había muerto unos pocos ańos antes. No. El «único Aldana» posible en ese contexto era Marco Antonio Aldana ${ }^{27}$. Como al comenzar este estudio, resulta evidente que los lectores modernos pasaron de un Aldana a otro.

Por otra, resulta indudable que también esa atribución debe ponerse en entredicho, pues la abundante tradición textual del poema parece negarla.

26. Antonio Rodríguez-Moñino, El capitán Francisco de Aldana, poeta del siglo XVI (15371578), p. 29; Elias L. Rivers, «Francisco de Aldana, el divino capitán», p. 573; Antonio Vilanova, ed., Andrés Rey de Artieda, Discursos, epistolas y epigramas de Artemidoro, Selecciones Bibliófilas, Barcelona, 1955, p. 74; Elias L. Rivers, ed., Francisco de Aldana, Poesías, p. Liv; José Simón Díaz, Bibliografia de la literatura hispánica, V, C.S.I.C., Madrid, 1973, p. 104; Gonzalo Díaz y Díaz, Hombres y documentos de la filosofía española, I, p. 80.

27. Repárese en que las famosas octavas sobre Angélica y Medoro del Cancionero de 1628, compilado en Zaragoza, aparecen atribuidas a "Aldana de Italia» (véase arriba, nota 8). En ese marco geográfico, cuando menos, parecía necesario hacer esa precisión, lo que es indicio de que al menos hacia el primer cuarto del siglo xviI se sabía de la existencia de otro Aldana poeta. 
Además de en los Discursos, epistolas y epigramas de Artemidoro, se recogió en doce manuscritos de los siglos xvi y xviı y en el Oratorio de enfermos de Juan Lorenzo Palmireno ${ }^{28}$, y en ellos, salvo una oscura atribución a Francisco de Figueroa, rápidamente puesta en duda, la única autoría que se presenta con ciertos visos de verosimilitud, refrendada por siete testimonios, es la de Damasio de Frías ${ }^{29}$. No es posible saber si Marco Antonio de Aldana se lo apropió vilmente o si, por el contrario, al rebuscar entre los papeles de su amigo, Andrés Rey de Artieda lo juzgó por suyo. En todo caso, debía circular por Valencia desde mucho tiempo atrás.

Quede aquí la presentación de Marco Antonio Aldana. Valga insistir, sin embargo, en que es el candidato ideal para recibir el fervoroso elogio de Gaspar Gil Polo. Militar y poeta de cierto renombre, cumple con el requisito indispensable de ser de Valencia o, al menos, de residir largas temporadas en esa ciudad (cuando menos, hasta el punto de que su amigo Juan Binimelis lo califique de "caballero valenciano»). Su conocimiento del italiano debió ser excelente, hasta el extremo de que se propuso su nombre para traducir algunas obras de ese idioma. Y, sobre todo, se encuentra perfectamente relacionado con el grupo de escritores valencianos de su época: Joan Timoneda lo menciona entre ellos, y lo poco que conocemos de su obra literaria se liga, indefectiblemente a ese mismo círculo literario. Así, el soneto en La Carolea de Jerónimo Sempere aparece junto a otras composiciones elogiosas de Gaspar Gil

28. La versión extensa del poema, compuesta por tres octavas, aparece en dos testimonios: Otavas a la muerte del principe don Carlos de Austria, del poeta Damasio de Frías, de Valladolid (Ravenna, Biblioteca Classense, ms. 263, f. 160v); Octavas a la muerte del príncipe don Carlos, hijo de Felipe Segundo (Peralada, Biblioteca del Castell, reg. 49481, f. 177r). La versión corta, de una sola octava, se recoge en once (doce, si se incluye un manuscrito hoy perdido): A la muerte del principe don Carlos, hijo de Felipe Segundo (The Hispanic Society of America, ms. HC 380/147, f. 77r); A morte do princepe don Carlos de Castella (Biblioteca Pública e Arquivo Distrital de Evora, ms. cxiv/2-2, f. 143v); A morte do príncipe dom Carlos de Castela (Biblioteca Nacional de Portugal, cod. F. G. 8920, f. 42r); De Damasio a la muerte del príncipe don Carlos (Biblioteca Nacional de España, ms. 4256, f. 262v); El mismo [Damasio de Frías] (Biblioteca de don Bartolomé March, 23/4/1, f. 210r); Epitafio a la sepultura del príncipe. Figueroa s[cripsit], ut alii dicunt Damas[i]o auctore (Biblioteca de la Real Academia de la Historia, ms. 9/5880, f. 240v); Epitafio a o sepulchro de Carlos filho del rey Philippe (The Hispanic Society of America, ms. B 2558, f. 59v); Octava y epitafio a la muerte del principe don Carlos, hijo de Felipe Segundo, por Damasio (Biblioteca Nacional de España, ms. 3926, f. 17v); Otava a la muerte del Principe (Real Biblioteca, ms. II-570, f. 271r; inserto precisamente en una colección de obras de Damasio de Frías); Oratorio de enfermos, con muchos consuelos y ejemplos de sanctos y oraciones devotas para alivio en enfermedades largas y dolorosas, por Juan Lorenzo Palmireno, Pedro de Huete a costa de Baltasar Simón, Valencia, 1580, p. 182; y en los ya mencionados Discursos, epistolas y epigramas de Artemidoro. Habría que añadir a este último grupo, como queda dicho, un manuscrito actualmente perdido pero mencionado por Bartolomé José Gallardo en el que también se afirmaba la autoría de Damasio de Frías: A la muerte del príncipe don Carlos, hijo de Felipe Segundo, por Damasio (Arthur Lee-Francis Askins, ed., The Hispano-Portuguese "Cancionero» of the Hispanic Society of America, University of North Carolina, Chapell Hill, 1971, p. 223).

29. Para todo este razonamiento, me baso en el excelente trabajo de Laura Fernández García, «Una nota a El rufián viudo», Boletín de la Real Academia Española, LXXXI, 2001, pp. 151-158, donde, gentilmente, la autora hizo un pequeño adelanto de este artículo. 
Polo, Miguel Jerónimo Oliver y Alonso Girón de Rebolledo. Los dos últimos, por supuesto, alabados unos años después en el Canto de Turia, que escribió el primero. En esta composición, a su vez, reaparecen Sempere y Andrés Rey de Artieda, a quien también dedicará un soneto. Y no estará de más recordar que tanto el sacerdote e historiador Juan Binimelis, a quien dedica otro, como el preceptor Domingo Andrés, quien le dedicó el epigrama latino, estudiaron en la universidad de Valencia. ${ }^{30}$ Una y otra vez, su actividad literaria lo liga a esa ciudad. No se equivocaba, pues, el bueno de Gaspar Gil Polo. Solo había que buscar un personaje que encajara con el perfil ofrecido, sin limitarse a repetir lo mismo que se había venido diciendo desde hace más de dos siglos ${ }^{31}$.

30. Amparo Felipo Orts y Francisca Miralles Vives, Colación de grados en la Universidad Valenciana Foral: graduados entre 1580-1611, Universitat de València, 2002, pp. 115 y 117.

31. El lector me disculpará, pero no resisto la tentación de terminar este estudio con un detalle sumamente ilustrativo de lo que afirmo. El magnífico estudio de Elias L. Rivers «Francisco de Aldana, el divino Capitán», base de toda la investigación posterior, se publicó, como queda dicho en la nota 4, en 1953. Acuda, sin embargo, a la mayoría de los numerosos trabajos que lo citan o lo incluyen en sus bibliografías, y comprobará que aparece casi siempre con fecha de $¡ 1956$ ! Y no estoy hablando de la tirada aparte, en forma de libro, sino del artículo publicado en el noveno volumen de la Revista de estudios extremeños. Pequeños lapsus como este, desde luego, apenas si tienen importancia, salvo cuando queda en evidencia, como en el presente caso, que la cita bibliográfica se ha ido copiando de estudio en estudio. ¿Para qué comprobar, revisar, en fin, cuando es tan fácil limitarse a copiar? 


\section{APÉNDICE}

\section{Y AL FINAL, GASPAR ALDANA}

Vicente Ximeno (véase arriba, nota 5) fue el primer estudioso que afirmó que Francisco de Aldana había nacido en Valencia. La noticia provenía, sin embargo, de unas informaciones equivocadas que le había suministrado Gregorio Mayans, y de una errada interpretación de la elegía In priscos et celebres Valentine Regni Poetas qui alicuam operum floruerunt prostantia, tum Latino carmine, tum etiam \& vulgari que había incluido Vicente Mariner en su traducción al latín de las poesías de Ausiàs March ${ }^{32}$. En esta composición, en efecto, el traductor se complace en recordar los grandes intelectuales del Renacimiento (Juan Luis Vives, Jaime Juan Falcó, Lorenzo Palmireno...), los historiadores (Gaspar Juan Escolano...) los autores dramáticos (Cristóbal de Virués, Guillem de Castro, Francisco Agustín Tárrega, Gaspar Aguilar...) y los poetas más destacados del círculo valenciano (Jerónimo Sempere, Juan Andrés Núnez...). Pero el Aldana ahí aludido, significativamente, no aparecía junto a estos últimos, sino arropado por otros personajes:

Lombardi explicuit divinus verba Salaia atque anima totam vimque iubarque docet.

Emicat egregius Assensius undique verbis, dum Thomæ decorat mente, sinusque scholam.

Est Aldana suo foelix ubicumque boatu et valvas aperit iam Sophiæ nitidas.

Dum Thome libros Oromirus explicat altos et mundus discit, \& polus ipse tacet.

Iam Castaneda Sophiæ inter emicat ardeus et puram Thomæ donam habere viam ${ }^{33}$.

Las autoridades citadas hablan por sí mismas. No estaría mal contemplar la poesía de Francisco de Aldana a la luz de las obras de Pedro Lombardo o Santo Tomás de Aquino, pero resulta evidente que, en este fragmento, Vicente Mariner elogia a un grupo de profesores de teología de la Universidad de Valencia que desempeñaron su actividad en la segunda mitad del siglo xvI: Juan Lorenzo de Celaya o Salaya, doctor por la Universidad de París (1522), catedrático de teología y rector perpetuo del estudio valenciano (1525-1558), autor de unos comentarios a los cuatro libros de sentencias de Pedro Lombardo impresos entre 1528 y 1531; Pedro Juan Asensi, examinador de teología (1580-1610); Dionisio Oromir, catedrático de lógica (1573), cuestiones (1574), súmulas (1576) y filosofía (1578 y 1587), y Pedro Castañeda, catedrático de súmulas (1589), cuestiones (1590), filosofía (1591), filosofía moral (1593) y sentencias (1594) ${ }^{34}$.

Junto a ellos ejerció la docencia su compañero Gaspar Aldana (1544-1594). Por descontado, este teólogo aparece abundantemente documentado en esa universidad. Allí obtuvo el grado de bachiller y maestro en artes (1566), y desempeñó los cargos de examinador de artes (1572) y

32. Vicentii Marinerii Valentini, Opera omnia poetica et oratoria in IX libros divisa, Ludovicum Phillhet, Tournon, 1633, pp. 520-541.

33. Ibidem, pp. 528-529.

34. Amparo Felipo, La Universidad de Valencia durante el siglo XVI (1499-1611), Universitat de València, 1993, pp. 32-35...; Amparo Felipo Orts y Francisca Miralles Vives, Colación de grados en la Universidad Valenciana Foral: graduados entre 1580-1611, pp. 86, 87, 88, 90... (los completos índices onomásticos de ambas obras me eximen de ofrecer una lista larguísima de páginas, que reservo para la siguiente nota). 
teología (1577), catedrático de súmulas (1572), de filosofía (1574), de cuestiones (1576) y de teología $(1580)^{35}$. En 1575 realizó una importante declaración sobre la autonomía jurídica de la Universidad de Valencia ${ }^{36}$. Paralelamente, fue calificador del Santo Oficio ${ }^{37}$. No se trataba precisamente de un desconocido en la república de las letras, pues había firmado un buen número de aprobaciones para libros impresos ${ }^{38}$. Tampoco en este caso, pues, se había equivocado Vicente Mariner. Que con el paso del tiempo su poema fuera malinterpretado y que esa mala interpretación diera pie -junto al Canto de Turia- a que surgiera un error que ha pervivido casi hasta nuestros días (esto es, que Francisco de Aldana era valenciano), es otra cosa y no se le puede acusar por ello. A quienes no supieron o no se molestaron en leer su elegía, sin embargo, sí.

35. Amparo Felipo, La Universidad de Valencia durante el siglo XVI (1499-1611), pp. 114, 118, 120, 162, 171, 196, 197, 205, 206; Amparo Felipo Orts y Francisca Miralles Vives, Colación de grados en la Universidad Valenciana Foral: graduados entre 1580-1611, pp. 75, 86, 87, 117, 134, 170, 171, 173, 174, 175, 179, 181, 203, 251, 277, 278, 279, 280, 281, 282, 302, 303, 305.

36.Vicente Graullera Sanz, «El Fuero Universitario en la Valencia del siglo XVI», Anuario de historia del derecho, LXIII-LXIV (1993-1994), pp. 957-984 (en concreto, 973-975).

37. Valencia, 5-XII-1590: Los inquisidores Pedro Girón y Pedro Pacheco presentan al Consejo General una relación de candidatos para los oficios de consultores ordinarios, consultores extraordinarios y calificadores de la Inquisición. Entre estos últimos destaca «el maestro Aldana», «hombre doto y virtuoso y en quien a nuestro parecer concurren las cualidades necesarias» (Archivo Histórico Nacional, Inquisición, libro 917, ff. 5-10; la citas, en ff. 7r y 8v). Véanse también María Soledad Carrasco Urgoiti, El problema morisco en Aragón al comienzo del reinado de Felipe II, p. 116, y Ricardo García Cárcel, Herejía y sociedad en el siglo XVI: La Inquisición en Valencia 1530-1609, pp. 92 y 135.

38. Valga citar, por ejemplo, las que traen los siguientes volúmenes: Bernardo Gómez Miedes, De constantia, sive de vero statu hominis, Viuda de Pedro Huete, Valencia, 1586 (Valencia, 19IX-1586); Jerónimo Casado, Tratado de la satisfactión, Herederos de Juan Navarro, Valencia, 1591 (Valencia, 9-Ix.1590); fray Juan Benito Guardiola, Tratado de nobleza, y de los títulos y ditados que hoy día tienen los varones claros y grandes de España, Viuda de Alonso Gómez, Madrid, 1591 (Madrid, 27-XI-1590); fray Diego de Estella, Libro de las excelencias, y vida de San Juan Evangelista, Herederos de Juan Navarro, Valencia, 1595 (Valencia, 10-XII-1591). 